\title{
Laparoscopic Repair of an Incidental Morgagni Hernia During Roux-En-Y Gastric Bypass in A Severe Obese Adult: A Case Report
}

\section{Robin A. Debi ${ }^{1}$ | Kamilcan Oflazoglu ${ }^{1,2}$ | Ruben Schouten ${ }^{1}$ | Stef J. M. Smeets ${ }^{1 *}$}

\author{
*Correspondence: Stef J.M. Smeets
}

Address: ${ }^{1}$ Department of Surgery; Flevoziekenhuis, Almere, The Netherlands; ${ }^{2}$ Department of Plastic, Reconstructive and Hand Surgery; Amsterdam UMC, Location VUmc, Amsterdam, The Netherlands

e-mail $\bowtie$ : ssmeets@flevoziekenhuis.nl

Received: 13 January 2021; Accepted: 25 January 2021

Copyright: (C) 2021 Debi RA. This is an open-access article distributed under the terms of the Creative Commons Attribution License, which permits unrestricted use, distribution, and reproduction in any medium, provided that the original work is properly cited.

\section{ABSTRACT}

A Morgagni hernia was found in a 53-year-old male patient during a laparoscopic Roux-en-Y gastric bypass procedure. The hernia was closed using a direct suturing technique. The hernial sac was not excised. A 12-month follow-up showed no hernia recurrence. This case indicated that laparoscopic approach is a suitable and safe procedure for treatment of Morgagni's hernia in obese patients.

Keywords: Morgagni Hernia; Bariatric Surgery; Incidental Hernia

\section{Introduction}

Roux-en-Y gastric bypass (RYGB) is a widely performed primary bariatric procedure in the world with almost 200.000 procedures in 2016 (Angrisani et al., 2017; IFSO, 2017). During this procedure, a small stomach pouch is created and connected directly to the small intestine to restrict food intake and reduce caloric absorption, followed by connecting the biliopancreatic and alimentary limbs, and closure of the mesenteric defects. The procedure is performed laparoscopically through 5 small horizontal incisions in the upper abdomen and usually takes about an hour to complete (Schlottmann and Buxhoeveden, 2018; Mingrone et al., 2012). Several types of laparoscopic bariatric procedures exist, e.g., sleeve gastrectomy (Rosenthal and Panel, 2012), adjustable gastric banding (O’Brien et al., 2019), One Anastomosis Gastric Bypass (Rutledge, 2001), Biliopancreatic Diversion with Duodenal Switch (Hess and Hess, 1998), and Single Anastomosis Duodenal-Ileal bypass with Sleeve, derived from the biliopancreatic diversion (Sánchez-Pernaute et al., 2007). During these laparoscopic procedures, rare anatomical findings can occur.

One of these extreme rare findings are congenital Morgagni hernias in which an incomplete fusion of the muscle fibers of the sternum and the costal margin leads to a triangular-shaped defect behind the 
xiphoid process (Angrisani et al., 2007; Young et al., 2019; Aghajanzadeh et al., 2012; Horton et al., 2008). Incidence of this hernia represents up to $5 \%$ of surgically treated diaphragm hernias. Treatment consists of direct suturing (Young et al., 2019; Aghajanzadeh et al., 2012; Dalvi et al., 2001).

\section{Case Report}

\section{Case History}

A 53-year-old man was referred to our center for bariatric surgery due to morbid obesity with a Body Mass Index (BMI) of 42.6. The patient suffered from dyspnea d'effort and cardiac and pulmonary examinations diagnosed the patient with Obstructive Sleep Apnea Syndrome (OSAS), treated with continuous positive airway pressure (CPAP) therapy. He reported no medication use, allergies, additional comorbidities and had no prior surgical history. He completed the bariatric screening program by the Bariatric Multidisciplinary Team (BMDT) a few months later and started preoperative counseling with a dietician and a two-month prehabilitation program under supervision of a physical therapist in group setting. Nine months after initial referral, the patient was admitted for the Roux-en-Y gastric bypass procedure.

\section{Laparoscopic Procedure}

According to our standard RYGB procedure, French position was applied at $45^{\circ}$ antiTrendelenburg. Closed CO2 pneumoperitoneum (15 mmHg) was performed with a Veress needle. A $12 \mathrm{~mm}$ trocar was placed in midline approximately $20 \mathrm{~cm}$ below the xiphoid process and used for optical introduction. Four additional trocars were placed in the right and left axillar (5mm) lines below the costal arch and two trocars in the midclavicular line $(12 \mathrm{~mm})$. When identifying anatomical structures after introduction, the transverse colon seemed to disappear in a space ventral to the right liver lobe. Approximately one meter of colon, gastric antrum and a large bulk of omentum were retracted. A large diaphragmatic defect was detected, which created a cavity ventral to the heart in the left mediastinum (Fig. 1).

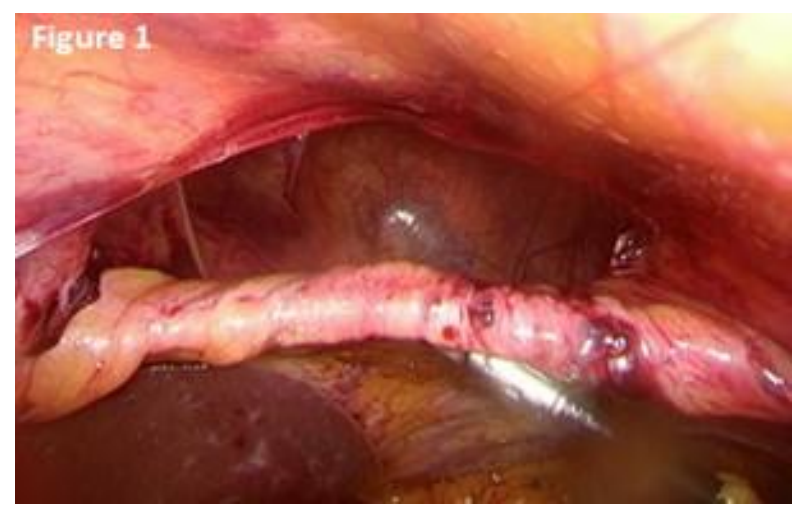

Figure 1: A large diaphragmatic defect was detected, which created a cavity ventral to the heart in the left mediastinum. 
Due to a large defect and weak ventral support tissue dorsal of the rib and retrosternal peritoneum, simple separated suture technique was applied with non-resorbable monofilament (ethibond excel 0, Ethicon, Johnson \& Johnson, US). To reinforce the closure, a Keith needle was positioned percutaneously through the abdominal wall into the peritoneal cavity and brought back over one of the ventral costae with respect to the neurovascular bundle to create a "hang- up" construction at the middle part of the defect. The suture was tied percutaneously outside the peritoneal cavity, ventral to the costal cartilage. The closure was finalized by using a running V-loc 2-0 suture (Medtronic, US; (Fig. 2). No mesh was used and the hernia sac was not resected. Finally, we proceeded with a standard Roux-en-Y gastric bypass with an alimentary limb of $75 \mathrm{~cm}$ and a biliopancreatic limp of $150 \mathrm{~cm}$. Total duration of surgery was 150 minutes.

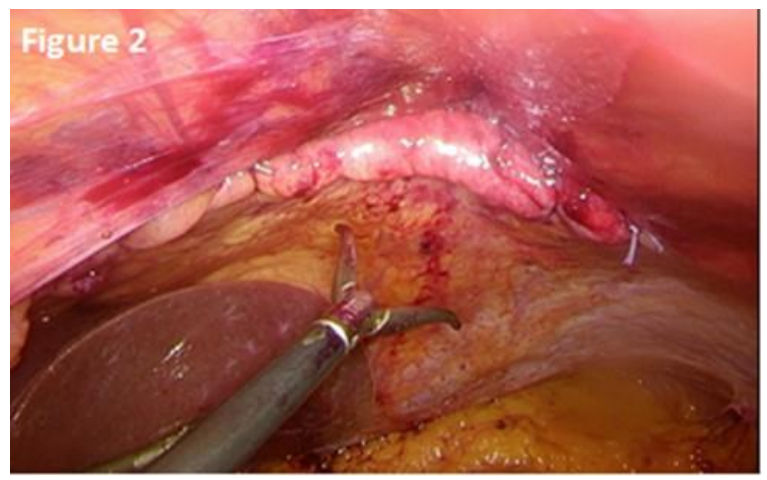

Figure 2: The suture was tied percutaneously outside the peritoneal cavity, ventral to the costal cartilage. The closure was finalized by using a running V-loc 2-0 suture.

Follow Up

Direct postoperatively, after explaining these findings to the patient and his partner, he was positively surprised and he immediately noted improved in- and exhale excursions. He revealed that he was treated for dyspnea in a rural teaching hospital 4 years earlier. The requested tomography showed a diaphragmatic herniation with fatty tissue (omentum or lipoma) located in the hernia sac, stated in the tomography report. No further treatment was indicated, because the dyspnea was thought to be directly associated with the obesity or obesity hypoventilation syndrome (OHS).

At 12-month follow up, he lost $57 \mathrm{~kg}$ (BMI of 27). Patient remarkably did not report any dyspnea or related respiratory complaints, and CPAP therapy was stopped shortly after the procedure. At 7 months postoperatively a computed tomography (CT) showed a much smaller pocket with seroma ventral to the mediastinum (Fig. 3 and Fig. 4). 


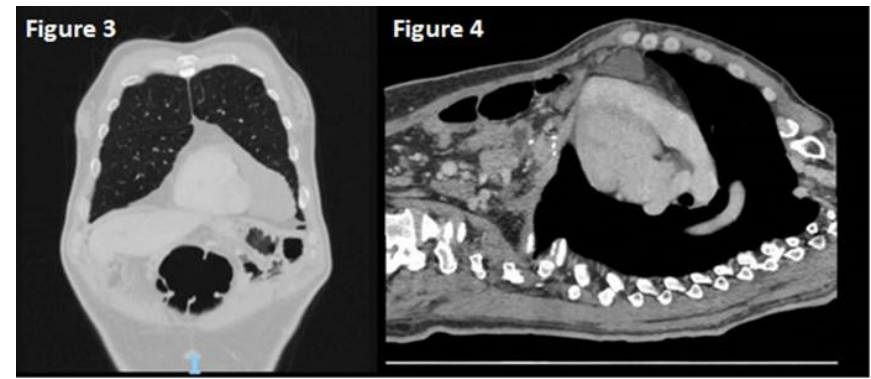

Figure $3 \& 4$ : A computed tomography (CT) showed a much smaller pocket with seroma ventral to the mediastinum.

\section{Discussion}

The location of a Morgagni hernia occurs posterolaterally to the sternum to either the left or right of the xiphoid rocess as a result of failure of the pars tendinalis part of the costochondral arches to fuse with the pars sternalis, resulting in an incomplete formation of the diaphragm (Nasr and Fecteau, 2009; Loong and Kocher, 2005; Al-Salem, 2007). This hernia is associated with obesity and is often diagnosed in adulthood, which is unusual for a congenital disorder (Aghajanzadeh, 2012; Harris et al., 1993). There are three types of Morgagni hernias: most common is right-sided (91\%), followed by bilateral and left sided (Aghajanzadeh, 2012; Horton et al., 2008; Sanford et al., 2018). Morgagni hernias usually have a developed peritoneal sac which can contain intra-abdominal organs, e.g. colon, omentum, stomach, liver and small bowel.18 Clinical presentation mostly consists of respiratory complaints with dyspnea, cough, or retrosternal pain, followed by gastro-intestinal pain or obstruction (Young et al., 2019; Horton et al., 2008; Harris et al., 1993; Pfannschmidt et al., 2004). Complications such as strangulation or incarceration are uncommon and require immediate surgical treatment (Angrisani et al., 2000; Horton et al., 2008; Sanford et al., 2018; Lee et al., 2016).

Different surgical approaches have been described: transthoracic and transabdominal. In obese patients a transthoracic approach may be easier to access the hernial sac (Horton et al., 2008). In this case report we applied a transabdominal laparoscopic approach in a surgical set-up for upper gastrointestinal surgery. Since a Morgagni hernia is a ventral defect, the large amount of intra-abdominal fat does not bother the repair too much and reducing the hernia content is easier. Pfannenschimdt, et al. emphasizes the safety and effectiveness of this abdominal approach in the repair of Morgagni hernia in a series of seven patients, of which 4 with a BMI >30 (Pfannschmidt et al., 2004). Three major laparoscopic techniques have been described; closure with a mesh (Dogaru et al., 2016), using a Keith needle (Newman et al., 1995; Park and Doyle, 2014), or direct suturing10. All three techniques previously mentioned have proven to be successful. However, there are differences in approach and execution. Closure with a mesh is considered for large defects and requires to leave a foreign body or the use of more expensive options such as biological or biosynthetic mesh types (Dogaru et al., 2016). 
The use of a Keith needle appears to be more sensitive for iatrogenic injury and pain (Newman et al., 1995). In a previous case report of Kuster, et al. a laparoscopic Morgagni hernia repair was performed by nonabsorbable monofilament with continuous suture joining the subcostal and retrosternal peritoneum to the full thickness of the diaphragmatic edge. A small skin incision was used to incorporate the fascia of the rectus abdominis in the repair and sutures were tied by extracorporeal knotting (Kuster et al., 1992). In this case report we applied a mixture of techniques using direct suturing with separate stitches to prevent tear, an anchoring fixation around the rib with a Keith needle and running stitches with V-loc in between to strengthen the repair. In this way we were able to close a large hernia in a morbidly obese patient without using a mesh. As in most cases in literature, we did not resect the intrathoracic peritoneal sac, because of its tremendous size and proximity to the pericardium, which could lead to a massive pneumomediastinum, pneumopericardium or infection (Angrisani et al., 2000; Sanford et al., 2018; Johnson, 1949; Pokorny et al., 1984). Some case reports state an uneventful resection of the peritoneal sac (Newman et al., 1995; Rau et al., 1994; Fernandez-Cebrian et al., 1996).

\section{Conclusion}

In this laparoscopic approach with 12 months follow-up, we elucidated that a direct suturing technique of Morgagni hernia repair can be performed safely without resection of hernial sac nor usage of a mesh, in a morbidly obese patient. Furthermore, it shows that Morgagni hernia repair can safely be combined with other laparoscopic surgery such as gastric bypass.

\section{References}

Aghajanzadeh M, Khadem S, Khajeh Jahromi S, Gorabi HE, Ebrahimi H, Maafi AA. Clinical presentation and operative repair of Morgagni hernia. Interact Cardiovasc Thorac Surg 2012; 15: 608-611.

Al-Salem AH. Congenital hernia of Morgagni in infants and children. J Pediatr Surg 2007; 42: 1539-1543.

Angrisani L, Lorenzo M, Santoro T, Sodano A, Tesauro B. Hernia of foramen of Morgagni in adult: case report of laparoscopic repair. JSLS 2000; 4: 177-181.

Angrisani L, Santonicola A, Iovino P, Vitiello A, Higa K, Himpens J, Buchwald H, Scopinaro NI. IFSO Worldwide Survey 2016: Primary, Endoluminal, and Revisional Procedures. Obes Surg 2018; 28: 3783-3794.

Dalvi AN, Rege SA, Ravikiran CS, Thapar BV, Deshpande AA. Laparoscopic repair of Morgagni hernia in adult. Indian J Gastroenterol 2001; 20: 70.

Dogaru I, Avram M, Gherghinoiu M. Laparoscopic repair of morgagni hernia. Arch Balk Med Union 2016; 51: 532-535.

Fernandez-Cebrian JM and De Oteyza JP. Laparoscopic repair of hernia of foramen of Morgagni: a new case report. $J$ Laparoendosc Surg 1996; 6: 61-64.

Harris GJ, Soper RT, Kimura KK. Foramen of Morgagni hernia in identical twins: is this an inheritable defect? J Pediatr Surg 1993; 28: 177-178.

Hess DS and Hess DW. Biliopancreatic diversion with a duodenal switch. Obes Surg 1998; 8: 267-282. 
Horton JD, Hofmann LJ, Hetz SP. Presentation and management of Morgagni hernias in adults: a review of 298 cases. Surg Endosc 2008; 22: 1413-1420.

IFSO 2017 22(nd) World Congress. Obes Surg 2017; 27: 1-1253.

Johnson WW. Diaphragmatic hernia through the foramen of Morgagni. N Y State J Med 1949; 49: 1842-1844.

Kuster GG, Kline LE, Garzo G. Diaphragmatic hernia through the foramen of Morgagni: laparoscopic repair case report. $J$ Laparoendosc Surg 1992; 2: 93-100.

Lee JH, Nguyen QN, Le QA. Comparative effectiveness of 3 bariatric surgery procedures: Roux-en-Y gastric bypass, laparoscopic adjustable gastric band, and sleeve gastrectomy. Surg Obes Relat Dis 2016;12: 997-1002.

Loong TP and Kocher HM. Clinical presentation and operative repair of hernia of Morgagni. Postgrad Med J 2005; 81: 4144.

Mingrone G, Panunzi S, De Gaetano A, Guidone C, Iaconelli A, Leccesi L, Nanni G, Pomp A, Castagneto M, Ghirlanda G, Rubino F. Bariatric surgery versus conventional medical therapy for type 2 diabetes. N Engl J Med 2012; 366: 1577-1585.

Nasr A and Fecteau A. Foramen of Morgagni hernia: presentation and treatment. Thorac Surg Clin 2009; 19: 463-468.

Newman 3rd L, Eubanks S, Bridges 2nd WM, Lucas G. Laparoscopic diagnosis and treatment of Morgagni hernia. Surg Laparosc Endosc 1995; 5: 27-31.

O’Brien PE, Hindle A, Brennan L, Skinner S, Burton P, Smith A, Crosthwaite G, Brown W. Long-Term Outcomes After Bariatric Surgery: A Systematic Review and Meta-analysis of Weight Loss at 10 or More Years for All Bariatric Procedures and a Single-Centre Review of 20-Year Outcomes After Adjustable Gastric Banding. Obes Surg 2019; 29: 3-14.

Park A and Doyle C. Laparoscopic Morgagni hernia repair: how I do it. J Gastrointest Surg 2014; 18: 1858-1862.

Pfannschmidt J, Hoffmann H, Dienemann H. Morgagni hernia in adults: results in 7 patients. Scand J Surg 2004; 93: 7781.

Pokorny WJ, McGill CW, Harberg FJ. Morgagni hernias during infancy: presentation and associated anomalies. J Pediatr Surg 1984; 19: 394-397.

Rau HG, Schardey HM, Lange V. Laparoscopic repair of a Morgagni hernia. Surg Endosc 1994; 8: 1439-1442.

Rosenthal RJ and Panel IS. International Sleeve Gastrectomy Expert Panel Consensus Statement: best practice guidelines based on experience of $>12,000$ cases. Surg Obes Relat Dis 2012; 8: 8-19.

Rutledge R. The mini-gastric bypass: experience with the first 1,274 cases. Obes Surg 2001; 11: 276-280.

Sánchez-Pernaute A, Herrera MA, Pérez-Aguirre E, Pérez JC, Cabrerizo L, Valladares LD, Fernández C, Talavera P, Torres A. Proximal duodenal-ileal end-to-side bypass with sleeve gastrectomy: proposed technique. Obes Surg 2007; 17: $1614-1618$.

Sanford Z, Weltz AS, Brown J, Shockcor N, Wu N, Park AE. Morgagni Hernia Repair: A Review. Surg Innov 2018; 25: 389399.

Schlottmann F and Buxhoeveden R. Laparoscopic Roux-en-Y Gastric Bypass: Surgical Technique and Tips for Success. $J$ Laparoendosc Adv Surg Tech A 2018; 28: 938-943.

Young MC, Saddoughi SA, Aho JM, Harmsen WS, Allen MS, Blackmon SH, Cassivi SD, Nichols FC, Shen KR, Wigle DA. Comparison of Laparoscopic Versus Open Surgical Management of Morgagni Hernia. Ann Thorac Surg 2019; 107: $257-261$. 